\title{
Pre-Print Diagnostic Cases in Pre-Service Teacher Education: Effects of Text Characteristics and Empathy on Text-Based Cognitive Models
}

\author{
Alexander Wedel ${ }^{\mathrm{a}}$, Christin R. Müller ${ }^{\mathrm{b}}$, Franziska Greiner ${ }^{\mathrm{c}}$ \\ ${ }^{a}$ Technische Universität Berlin, Department of Educational Psychology \\ ${ }^{\mathrm{b}}$ Independent Researcher, Berlin \\ ${ }^{c}$ Friedrich Schiller University Jena, Department of Educational Psychology
}

\section{Author Note}

Alexander Wedel (iD) https://orcid.org/0000-0002-6909-0863
Christin R. Müller (iD $\underline{\text { https://orcid.org/0000-0003-1486-2528 }}$
Franziska Greiner (iD $\underline{\text { https://orcid.org/0000-0002-4585-5315 }}$

Correspondence concerning this article should be addressed to Alexander Wedel, Technische Universität Berlin, Institute of Education, MAR 2-6, Marchstraße 23, 10587 Berlin (Germany). E-Mail: alexander.wedel@tu-berlin.de 


\begin{abstract}
In teacher education, case-based learning is an efficient method to foster pre-service teachers' diagnostic competence. To adaptively utilize text-based cases, knowledge about the effect of text characteristics is needed, but still scarce. The present study focuses on the effects of two text characteristics - text style and text subject - and on the effect of empathy on the accuracy of case-based cognitive models. This was examined with an experimental design, in which 391 pre-service teachers read a case in either psycho-narrative or externally focalized style (text style) about test anxiety or dyscalculia (text subject). Afterwards, state-empathy was measured by self-report and cognitive models were assessed with a recognition and verification test. Regression analyses showed no main effects of text characteristics, but moderation effects for text style and affective state-empathy. Implications are drawn for adaptively designing textbased cases and for possible mechanisms of how empathy is involved in diagnostic judgement formation.
\end{abstract}

Keywords: teacher education, diagnostic competence, text comprehension, cognitive modelling, empathy 


\section{Diagnostic cases in pre-service teacher education: Effects of text characteristics and empathy on text-based cognitive models.}

Developing and evaluating evidence-based learning environments to acquire diagnostic competence is an ongoing challenge in teacher education. Evaluation and intervention studies show beneficial effects of case-based learning on pre-service teachers' domain specific knowledge, beliefs, abilities and motivation (Chernikova et al., 2019; Schäfer \& Seidel, 2015). Cases are mostly video- or text-based, resembling the demands of diagnostic activities both inside and outside the classroom, i.e. processing information from classroom interactions, students' homework and psychological test results (Schneider et al., 2016; Syring et al., 2015; Wedel et al., 2020). Preparing pre-service teachers with text-based cases is sensible, since teachers not only see their students' behavior, but also read and collect their task and test answers as well as other written documents related to their academic and social behavior for ongoing diagnostic purposes (Marks et al., 1995). Although text-comprehension plays a crucial role in the diagnostic process and in interventions to increase diagnostic competence, there is very limited knowledge about how specific text characteristics affect the processing of textbased diagnostic information (Böhmer et al., 2015). Moreover, although strategically utilizing emotions can be highly beneficial for information processing and memorizing (Gaesser, 2013), there are no studies on the effects of pre-service teachers' empathy on processing text-based diagnostic information. The present study addresses these considerations and adds to the empirical knowledge about pre-service teachers' diagnostic competence.

\section{Teachers' Diagnostics and Cognitive Modeling}

In order to provide effective learning environments in school classes, teachers collect, process, organize and integrate information about their students learning and performance. Teacher education addresses these demands by fostering diagnostic competence. Klug et al. (2018) define diagnostic competence as effectively collecting, interpreting and utilizing information about students' learning process, preconditions and disorders to make accurate judgements and to foster students' self-regulated learning behavior. They follow Blömeke et al. (2015), who conceptualize competence as cognitive abilities, including context specific perception, interpretation and reasoning skills. That is, teachers with high diagnostic competence are expected to be able to effectively and accurately memorize, retrieve and utilize information about students' learning prerequisites, processes and outcomes.

This definition of Klug et al. (2018) and other recent models of teachers' diagnostic competence (e.g. Leuders et al., 2018; Ostermann, 2018) consider cognitive modeling of students' learning prerequisites and subject knowledge as an integral part of the diagnostic process. Cognitive modeling refers to building case-based knowledge about specific students (or problems) as well as integrating it with general theoretical knowledge to construct causal relationships and predictive inferences (Calvo et al, 2006).

The concept of case-based knowledge is closely related to research on expertise, showing that building elaborate cognitive models is much more pronounced in expert teachers, than in novice teachers (Bradley et al., 2006; Strauss \& Shilony, 1994). Thus, identifying individual and situational predictors of elaborate cognitive modeling can inform the design of effective case-based interventions for training diagnostic competence. 


\section{Working with Text-Based Cases in Teacher Education}

Following the results of research on expertise, case-based learning in teacher education aims at developing knowledge that is organized around cognitive models of specific cases. Cases, in turn, are often text-based, e.g. students' homework or test answers, documentation of other teachers, psychologists or social workers (Leuders et al., 2018). Accordingly, text-based cases play a crucial role in educational practice and research. They are used for research on teachers' competence, either as experimental material (e.g. Bohl et al., 2016; Glock et al., 2013; Wedel et al., 2019) or as (part of) measurement instruments (e.g. Klug et al., 2013; Kunter et al., 2017). Thus, cognitive modeling and understanding of cases is a central part of both, the diagnostic process and case-based learning.

Currently, there is no empirical data on pre-service teachers' cognitive modeling skills. Several intervention studies show that working with text-based cases increases pre-service teachers' interpretation and reasoning skills (Chernikova et al., 2019; Wedel et al., 2019), and that these skills are often related to more elaborate cognitive models (Calvo et al., 2006). Still, a deeper understanding of how text characteristics affect cognitive modeling is hard to gain, as the text-based cases are designed differently in every study. Syring et al. (2016) used narratively enriched transcripts of classroom videos, other studies used narrative descriptions of classroom situations (Heitzmann et al., 2017; Kiel et al., 2014), or narrative descriptions with additional diagnostic material (Wedel et al., 2019). Thus, we do not know, to what extent intervention effects depend on the design of the text-based cases and whether the design has a causal influence on the degree of elaboration, in which pre-service teachers build up cognitive models from such cases.

A theoretical framework for investigating cognitive modeling and information processing based on text material is the construction-integration theory (Kintsch, 1992). The theory proposes that three forms of cognitive models are built up simultaneously (Aryadoust, 2019): (1) a verbatim model, containing exact words and sentences of the text, (2) a propositional model, containing the meaning of text parts and their relation to each other, and (3) a situational model, containing causal relationships, courses of action and additional information from longterm memory (Singer \& Kintsch, 2001). We employ this framework to measure the outcome of pre-service teachers' cognitive modeling activities with a recognition and verification test.

\section{The Role of Empathy for Diagnostic Competence and Working with Text-Based Cases}

Research on case-based interventions to foster teachers' diagnostic competence has focused on dispositions correlated with accurate judgments of students' subject knowledge and learning prerequisites, most importantly theoretical knowledge and motivation (Chernikova et al., 2019; Trittel et al., 2011; Seidel et al., 2010). Empathy, however, has rarely been considered as a social-cognitive disposition for performing diagnostic activities and specifically for building accurate and elaborate cognitive models of students' learning cognitions and emotions.

Empathy is defined as a trainable, vicarious reaction to observed emotional experiences of others and is commonly described by its cognitive and affective components (Eisenberg, 2000). The cognitive component represents the ability to understand the mental states, thinking and reasoning of others (e.g. by simulating another person's mental state or point of view). The affective component represents the ability to understand others' positive or negative emotional states, which is often accompanied by emotional arousal. Both components include the ability 
to distinguish between one's own and someone else's cognitive and affective reactions (Decety \& Lamm, 2006). Empathy has been approached both as a stable personality trait as well as a situational mental state. While trait-empathy refers to a personality characteristic that is stable over time and across situations, state-empathy has been defined as a situationally determined stimulation or prohibition of building cognitive models about another person's mental state (Preston \& de Waal, 2002).

Studies show that in their diagnostic activities teachers benefit from empathy Park \& Hwang, 2013; Tsoulopas et al., 2014) with the effect being stronger for expert than for novice teachers (Knutson-Miller, 2001; Hellmann, 2015; Teuscher et al., 2016). But is this effect also evident in the text-based training of pre-service teachers' diagnostic competence?

Text-based cases mostly include a narrative description of a teaching situation and the people involved, including their intentions, thoughts and feelings (Kiel et al., 2014). Empathy caters to these core elements. Though there are studies investigating the relationship between text characteristics and text comprehension, as well as the relationship between text characteristics and empathy, no studies address all three constructs at the same time. Specifically, Gernsbacher et al. (1992) demonstrated that texts including characters and courses of action automatically lead to building cognitive models of the fictional characters' mental and emotional states. Furthermore, Salem et al. (2017) showed that text styles differentially trigger empathic reactions. These empathic reactions were stronger, when participants read texts including personal thoughts and feelings, i.e. texts in psycho-narrative style.

Research from cognitive psychology generally supports positive effects of cognitive trait- and state-empathy on processing person-specific information (Stiller \& Dunbar, 2013; Gao et al., 2016). This effect has also been shown for affective state-empathy, but less for affective traitempathy (Lombardo et al., 2007; Gao et al., 2016; Wagner et al., 2015).

\section{Hypotheses}

Accordingly, we assume that instructional material for promoting pre-service teachers' diagnostic competence including social information (e.g. thoughts, feelings), has a positive effect on the strength of cognitive models. Furthermore, this effect should be strengthened by higher affective or cognitive state-empathy. Since empathy relates to others' emotional responses, its positive effect should be stronger for cases about affective learning problems (e.g. text anxiety), rather than for cases about cognitive learning problems (e.g. dyscalculia). Based on these assumptions, we phrased the following hypotheses:

(1) The psycho-narrative text style has a stronger positive effect on the verbatim, propositional and situational model than the externally focalized text style.

(2) The text subject of test anxiety has a stronger positive effect on the verbatim, propositional and situational model than the text subject of dyscalculia.

(3) Affective state-empathy has a positive effect on the verbatim, propositional and situational model.

(4) Cognitive state- and trait-empathy have a positive effect on the verbatim, propositional and situational model.

(5) Cognitive or affective state-empathy moderate the effect of text style on the verbatim, propositional and situational model. 


\section{Methods \\ Study Design}

To test these hypotheses, we conducted a cross-sectional experimental online study. First, the participants answered a questionnaire on demographic variables and self-assessed affective and cognitive trait-empathy. Second, participants were randomly assigned to read a text-based case in either psycho-narrative or externally focalized style. To control for text subject effects, each case had either the subject of dyscalculia or test anxiety ( $2 \times 2$ design with four conditions). Third, participants answered a questionnaire on affective and cognitive state-empathy, immersion, thematic interest, and cognitive elaboration. Finally, to measure the strength of the cognitive models built, the participants answered a recognition and verification test. The study took place in a regular lecture and lasted 15-20 minutes.

\section{Participants}

The participants were $N=389$ pre-service teachers (73\% female) aged 18-43 years $(M=22.94, S D=5.23)$, recruited from four German universities (Jena, Berlin, Leipzig, and Potsdam). They were randomly assigned to one of the above mentioned four conditions. To ensure that the participants from the four universities did not systematically differ from one another, we conducted a set of ANOVAs. We found a significant difference between the students from Jena, Berlin, and Leipzig regarding sex and age, but not regarding the other variables. Therefore, we included sex and age as control variables in the subsequent regression analyses.

\section{Measures}

\section{Demographic Variables}

Sex and age, as well as the number of courses attended on diagnostics were assessed with one item each. Sex and age were assessed because they are standard control variables in educational research (e.g. PISA, TALIS, TIMSS). The number of courses served as a proxy variable for prior knowledge on diagnostics. The survey processing time was assessed using automated survey software and served as a control variable, because it has a direct effect on the specificity of cognitive models (Wang et al., 2017).

\section{Trait- and State-Empathy}

Trait-empathy was assessed using the Basic Empathy Scale (BES) by Heynen et al. (2016). The scale consists of 4 items for affective empathy $(M=1.97, S D=0.57, \alpha=.67)$ and 4 items for cognitive empathy $(M=2.35, S D=0.43, \alpha=.65)$, e.g. "I am easily influenced by the feelings of others." and "I often already understand how people feel before they tell me about it." Students rated the items on a 4-point Likert scale from $0=$ don't agree at all to $3=$ fully agree. From the original scale with 12 items, we excluded 4 items because of item-to-total correlations $<.30$ or very low reliabilities.

State-empathy was assessed with the State Empathy Scale by Shen (2010). The scale consists of 4 items for affective empathy $(M=2.02, S D=0.59, \alpha=.82)$ and 4 items for cognitive empathy $(M=1.78, S D=0.60, \alpha=.83)$, e.g. "I was in a similar emotional state as the teacher in the case when reading the text." and "I can understand what the teacher in the case was going through." Students rated the items on a 4-point Likert scale from $0=d o n ' t$ agree at all to $3=$ fully agree . 


\section{Text Cases}

Students either read a text-based case in psycho-narrative or externally focalized style about dyscalculia or test anxiety (see Table 1). The cases in psycho-narrative style used figurative language and described the teachers' thoughts and feelings, e.g. "Then suddenly the school file comes to your mind. You leaf through the file quite excited and discover a completed DAI questionnaire." The cases in externally focalized style focused on visible, external aspects of the narrative, e.g., "You take Friis' school file and leaf through it. At the DAI questionnaire you stop and look at the answers." The text cases about dyscalculia indicated difficulties in processing numbers, whereas the cases about test anxiety pointed to negative emotions in performance situations, e.g. "Friis has actually written thirty thousand-and-fifteen and painted a jumble of shapes on the block... Friis has rather low values in the emotional anxiety manifestation." or "But Friis also has very high levels of emotional anxiety manifestation." Except for these crucial details, the cases were quasi-identical (49-53 sentences, 608-674 words), and were presented sentence-wise in the recognition and verification test.

\section{Table 1}

Text Case Style Characteristics

\begin{tabular}{|c|c|c|c|}
\hline Characteristics & Description & Psycho-narrative & Externally focalized \\
\hline Point-of-view & $\begin{array}{l}\text { Perspective from which } \\
\text { information is } \\
\text { transferred to the reader }\end{array}$ & Second-person (you) & Second-person (you) \\
\hline $\begin{array}{l}\text { Treatment } \\
\text { scenes }\end{array}$ & $\begin{array}{l}\text { Mode of textual } \\
\text { information } \\
\text { representation }\end{array}$ & $\begin{array}{l}\text { Subjective treatment, } \\
\text { i.e. personal } \\
\text { interpretations }\end{array}$ & $\begin{array}{l}\text { Objective treatment, } \\
\text { i.e. } \\
\text { descriptions }\end{array}$ \\
\hline $\begin{array}{l}\text { a. Perceptual } \\
\text { facet }\end{array}$ & $\begin{array}{l}\text { Sensory perceptions } \\
\text { (what one hears, sees } \\
\text { etc.): }\end{array}$ & $\begin{array}{l}\text { Constrained to the } \\
\text { main character }\end{array}$ & $\begin{array}{l}\text { Observations of } \\
\text { behavior and moves }\end{array}$ \\
\hline $\begin{array}{l}\text { b. Psychological } \\
\text { facet }\end{array}$ & $\begin{array}{l}\text { Thoughts and feelings } \\
\text { constrained to: }\end{array}$ & Main character & None \\
\hline $\begin{array}{l}\text { c. Knowledge } \\
\text { facet }\end{array}$ & $\begin{array}{l}\text { Diagnostic information } \\
\text { presented through: }\end{array}$ & Main character & Narrator \\
\hline $\begin{array}{l}\text { d. Ideological } \\
\text { facet }\end{array}$ & $\begin{array}{l}\text { Expectations and values } \\
\text { expressed through: }\end{array}$ & $\begin{array}{l}\text { Characters in the } \\
\text { narration }\end{array}$ & Narrator \\
\hline
\end{tabular}




\section{Recognition and Verification Test}

According to signal detection theory, cognitive models can be measured objectively by correctly identifying actual information, i.e. signals, in the presence of similar, but 'false' information, i.e. noise (Snodgrass \& Corwin, 1988; Stanislaw \& Todorov, 1999). Applied to text-based cognitive models this means that participants are presented with multiple signal and noise items, which consist of single sentences (Schaffner \& Schiefele, 2013; Schiefele et al., 2000). For each item, participants must indicate, whether it has a pre-defined relationship to the text or not (yes/no).

According to the construction-integration theory, three relationships are of interest (Singer $\&$ Kintsch, 2001). Firstly, whether participants can recognize the exact wording of the sentence (signal/literal) and discriminate it from sentences having the same meaning, but different wording (noise/paraphrased). This is the verbatim model. Secondly, whether participants can verify sentences with changed wording but unchanged meaning (signal/paraphrased) and discriminate them from sentences with a changed, inferred meaning (noise/inference changed). This is the propositional model. Thirdly, whether participants can verify sentences with changed, but in the sense of the text possible inferred meaning (signal/changed inference) in the presence of sentences presenting information not in the text (noise/false sentences). This is the situational model. The verbatim, propositional and situational model are always built simultaneously but can vary in strength. Examples for literal, paraphrased, meaning changed and false sentences are given in Table 2.

\section{Table 2}

Example Items from the Recognition and Verification Test

\begin{tabular}{|c|c|c|}
\hline Sentence Type & Text sentence & Test sentence \\
\hline Literal & $\begin{array}{l}\text { But Friis also has very high } \\
\text { levels of emotional anxiety } \\
\text { manifestation. }\end{array}$ & $\begin{array}{l}\text { But Friis also has very high } \\
\text { levels of emotional anxiety } \\
\text { manifestation. }\end{array}$ \\
\hline Paraphrased & $\begin{array}{l}\text { Friis blushes and answers in a } \\
\text { loud and somewhat shaky } \\
\text { voice. }\end{array}$ & $\begin{array}{l}\text { Friis turns red and answers in } \\
\text { a somewhat shaky and loud } \\
\text { voice. }\end{array}$ \\
\hline Meaning changed & $\begin{array}{l}\text { You leaf through the file quite } \\
\text { excited and discover a } \\
\text { completed DAI questionnaire. }\end{array}$ & $\begin{array}{l}\text { You are very excited when } \\
\text { you see Friis' self-reports in } \\
\text { the DAI questionnaire. }\end{array}$ \\
\hline False & $\begin{array}{l}\text { Suddenly the door of the } \\
\text { teacher's room opens, and you } \\
\text { flinch. }\end{array}$ & $\begin{array}{l}\text { When you see Ms. Meier } \\
\text { come into the teacher's room, } \\
\text { you smile and wave her over. }\end{array}$ \\
\hline
\end{tabular}

Note. Example items were translated from German into English; DAI = Differential Anxiety Inventory (standard questionnaire measuring test anxiety, that is often employed in the school context).

The strength of each of the three models is calculated in several steps (Schmalhofer \& Glavanov, 1986). Firstly, the relative frequencies of correct answers for each sentence type in the test are calculated. For the signal items, this corresponds to the hit/miss rate in signal detection theory and gives the probability of signal detection with a range of $0-1$. For noise items, this corresponds to the correct rejection/false alarm rate and gives the probability of 
noise detection and equally a range of $0-1$. Secondly, the related discrimination index $d$ ' can be calculated by subtracting the probability of noise detection from the probability of signal detection. Since the probability curves of signal and noise detection can differ in their variability, $z$-scores of the relative frequencies are used in the calculations (Snodgrass \& Corwin, 1988). Thus, theoretically, $d$ '-scores can be infinitely high or low, but typically range between \pm 4 .00. The resulting difference score follows a linear interpretation, that is, a positive score relates to correctly detecting signals while at the same time correctly rejecting noise, i.e. an accurate verbatim, propositional or situational model of the text. A negative score indicates a confusion between signal and noise items, i.e. a false memorization. A $d$ ' score of 0 equals random chance, i.e. no discrimination between signal and noise.

Following this protocol, we constructed and implemented a recognition and verification test. The test consists of 28 sentences: 7 literal (1), 7 paraphrased (p), 7 meaning changed (m), and 7 false (f) sentences. Table 3 shows the means and standard deviations for the correct recognition and verification rates for each sentence. Higher recognition rates in 1 items than in $\mathrm{p}$ items, higher verification rates in $\mathrm{p}$ items than in $\mathrm{m}$ items, and higher verification rates in $\mathrm{m}$ items than in $\mathrm{f}$ items indicate that the measurement was successful (Schiefele et al., 2000). In our data, this was the case after excluding item 7 from each of the sentence types $(t$ verbatim model $(390)=28.23, p<.001 ; t$ propositional model $(390)=19.18, p<.001 ; t$ situational model $(390)=2.86$, $\mathrm{p}=.004)$. Therefore, the recognition and verification test performed according to the standard outlined by Schiefele, Artelt, Schneider and Stanat (2000), and we continued with the analyses.

\section{Table 3}

Means and Standard Deviations for Correct Recognition and Verification Rates, and Scales for d'-Value Calculation

\begin{tabular}{llllll}
\multicolumn{5}{l}{ Recognition task $^{\mathrm{a}}$} & \multicolumn{3}{l}{ Verification task } \\
\hline Sentence & Literal & Paraphrased & Paraphrased & Meaning Changed & False \\
\hline 1 & $.84(.37)$ & $.20(.40)$ & $.96(.20)$ & $.79(.41)$ & $.76(.43)$ \\
2 & $.84(.36)$ & $.31(.46)$ & $.89(.32)$ & $.52(.50)$ & $.55(.50)$ \\
3 & $.59(.49)$ & $.34(.48)$ & $.88(.32)$ & $.62(.49)$ & $.55(.50)$ \\
4 & $.71(.46)$ & $.20(.40)$ & $.94(.24)$ & $.64(.48)$ & $.61(.49)$ \\
5 & $.57(.50)$ & $.18(.38)$ & $.96(.20)$ & $.68(.47)$ & $.75(.44)$ \\
6 & $.62(.49)$ & $.27(.45)$ & $.92(.27)$ & $.85(.36)$ & $.57(.50)$ \\
7 & $.48(.50)$ & $.31(.46)$ & $.89(.31)$ & $.48(.50)$ & $.91(.29)$ \\
\hline Scale $(1-7)$ & $.66(.21)$ & $.26(.18)$ & $.92(.11)$ & $.65(.22)$ & $.67(.21)$ \\
Scale $(1-6)$ & $.70(.21)$ & $.25(.19)$ & $.92(.12)$ & $.68(.23)$ & $.63(.23)$ \\
\hline
\end{tabular}

Notes. Means and standard deviations are displayed for the sentences utilized for the $d$ '-value calculation (not displayed are for example recognition task for the meaning changed sentences); Range $0-1 ; N=389$.

${ }^{a}$ Recognition task $=$ Was the sentence literally in the text?

${ }^{\mathrm{b}}$ Verification task $=$ Was the sentence correct within the meaning of the text? 


\section{Immersion, Thematic Interest and Cognitive Elaboration}

Immersion was measured with the Transportation Scale Short Form by Appel et al. (2015). The scale consists of 6 items $(M=4.11, S D=1.06, \alpha=.86)$, e.g. "I could see myself in the scenery described in the text." Students rated the items on a 7-point Likert scale from $0=d o n$ ' $t$ agree at all to $6=$ fully agree. Immersion served as a control variable for empathy, since both constructs are closely related (Appel et al., 2015).

Thematic interest was measured with a scale by Schiefele (1991) on a 4-point Likert scale from $0=$ does not apply to $3=$ does apply. The scale contains 6 items about personal interest in the text $(M=1.78, S D=0.64, \alpha=.87)$, e.g. "I found the topic of the text exciting."

Cognitive elaboration was assessed with 4 items by Schiefele (1990) on a 4-point Likert scale from $0=$ does not apply to $3=$ does apply $(M=1.87, S D=0.56, \alpha=.60)$., e.g. "I tried to 'translate' what I read into my own words."

Thematic interest and cognitive elaboration served as control variables for the text comprehension and cognitive modeling, respectively, since both variables have been shown to predict text comprehension in the construction-integration framework (Schiefele et al., 2000).

\section{Analysis Approach}

To test the effect of text style, text subject, and the affective and cognitive trait- and stateempathy on the verbatim, propositional and situational cognitive models of the text-based cases, we conducted three identical multiple hierarchical regression analyses, one for each of the three cognitive models. The procedure is based on suggestions by Frazier et al. (2004). In the first step of the regression we entered the demographic control variables such as age, in the second step we entered other control variables such as immersion. According to the experimental design, in the third step we entered affective and cognitive trait empathy, in the fourth step text style and text subject, and in the fifth step affective and cognitive state empathy. In the sixth step we entered the potential moderation effects, to analyze whether the relationship between state empathy and the cognitive models differs depending on the text case style (i.e. whether the slopes differ from each other).

Subsequently, we examined and visualized the interaction effects with simple slope analyses in ModGraph (Jose, 2013). Simple slope analyses indicate whether a predictive relationship between state empathy and the cognitive models is significant for the psycho-narrative and the externally focalized text styles (i.e. whether regression slopes differ from zero). 


\section{Results}

Descriptive Results for Affective and Cognitive Trait- and State-Empathy, and the Cognitive Models

Descriptive results for the demographic and the control variables, affective and cognitive traitand state-empathy, and the cognitive models are displayed in Table 4. The demographic variables, the control variables and affective and cognitive trait-empathy did not differ between participants who read a psycho-narrative or an externally focalized text case. The affective and cognitive state-empathy were higher, and the propositional model was stronger after reading text-based cases in psycho-narrative style than in externally focalized style. On the other hand, the situational model was stronger after reading text-based cases in externally focalized style. None of the variables differed between participants who read a case about dyscalculia or test anxiety (not displayed in Table 4).

\section{Table 4}

Means and Standard Deviations for the Control Variables, for Trait- and State-Empathy, and for the Verbatim, Propositional, and Situational Cognitive Model (CM)

\begin{tabular}{llll}
\hline & Total & $\begin{array}{l}\text { Psycho-narrative } \\
\text { text case style }\end{array}$ & $\begin{array}{l}\text { Externally focalized } \\
\text { text case style }\end{array}$ \\
\hline Age & $M(S D)$ & $M(S D)$ & $M(S D)$ \\
Sex ${ }^{a}$ & $22.94(5.23)$ & $22.81(5.27)$ & $23.09(5.20)$ \\
Number of courses & $0.73(-)$ & $0.73(-)$ & $0.72(-)$ \\
Survey processing time (sec) & $2.23(3.49)$ & $2.22(3.94)$ & $2.24(2.91)$ \\
\hline Immersion & $862(213)$ & $869(210)$ & $855(217)$ \\
Thematic interest & $1.11(1,06)$ & $4.15(1.08)$ & $4.07(1.04)$ \\
Cognitive elaboration & $1.87(0.56)$ & $1.86(0.56)$ & $1.80(0.65)$ \\
\hline Affective trait empathy & $1.97(0.57)$ & $1.98(0.57)$ & $1.88(0.56)$ \\
Cognitive trait empathy & $2.35(0.43)$ & $2.35(0.43)$ & $2.95(0.56)$ \\
\hline Text case style ${ }^{a}$ & $0.53(0.50)$ & - & - \\
Text case subject ${ }^{a}$ & $0.55(0.50)$ & $0.54(0.50)$ & $0.56(0.50)$ \\
\hline Affective state empathy & $2.02(0.59)$ & $\mathbf{2 . 0 8}(0.57)$ & $\mathbf{1 . 9 5}(0.60)$ \\
Cognitive state empathy & $1.78(0.60)$ & $\mathbf{1 . 8 3}(0.61)$ & $\mathbf{1 . 7 1}(0.58)$ \\
\hline Verbatim CM & $0.04(1.54)$ & $0.12(1.55)$ & $-0.04(1.54)$ \\
Propositional CM & $-0.00(1.37)$ & $\mathbf{0 . 2 7}(1.29)$ & $\mathbf{- 0 . 3 1}(1.39)$ \\
Situational CM & $-0.01(1.59)$ & $-0.13(1.58)$ & $0.12(1.58)$ \\
\hline
\end{tabular}

Notes. Significant differences between cases styles are marked in bold, $t$-Tests with $p<.05$; sex $(0=$ male,

$1=$ female $)$, text case style $(0=$ externally focalized, $1=$ psycho-narrative $)$, text case subject $(0=$ dyscalculia,

$1=$ test anxiety); $184<N<389$.

${ }^{\text {a }}$ For the dichotomous variables, $M$ corresponds to the relative frequency, e.g. there are $73 \%$ females. 


\section{Effects of Affective and Cognitive Trait- and State-Empathy, Text Style and Text Subject on the Cognitive Models}

Effects of affective and cognitive trait- and state-empathy, text style and text subject on the cognitive models in the sixths step of the regression analyses are displayed in Table 5.

Affective and cognitive trait-empathy had no significant effect on the verbatim, propositional and situational model. When controlling for affective and cognitive trait-empathy (as well as for all other control variables), the text style had a significant positive effect on the propositional model. That is, the propositional model was stronger after reading a psychonarrative text than after reading an externally focalized text. The text case style had no significant effect on the verbatim and the situational model. The text case subject, on the other hand, had no significant effect on any of the three models. Affective and cognitive stateempathy, like affective and cognitive trait-empathy, had no significant effect on the verbatim, propositional and situational model.

Further, the text style and affective state-empathy had a significant negative moderation effect on the propositional model and a significant positive moderation effect on the situational model. However, regarding the situational model, it must be considered that the moderation effect did not explain significantly more variance of the situational model than the variables previously included in the regression analysis, and that the overall model in the sixths step of the regression analysis was not significant. 
Table 5

Multiple Hierarchical Regression Analysis of Verbatim, Propositional and Situational Cognitive Model (CM) on Trait- and State-Empathy, Text Case Style and Text Case Subject

\begin{tabular}{|c|c|c|c|}
\hline & Verbatim CM & Propositional CM & Situational CM \\
\hline & $\beta(p)$ & $\beta(p)$ & $\beta(p)$ \\
\hline Age & $.024(.679)$ & $.121(.032)$ & $-.011(.854)$ \\
\hline Sex & $.131(.026)$ & $-.020(.727)$ & $.038(.512)$ \\
\hline Number of courses & $.028(.613)$ & $.005(.918)$ & $-.002(.977)$ \\
\hline Survey processing time $(\mathrm{sec})$ & $.076(.173)$ & $.092(.086)$ & $-.088(.110)$ \\
\hline Immersion & $.104(.220)$ & $.178(.031)$ & $-.083(.327)$ \\
\hline Thematic interest & $-.009(.896)$ & $-.078(.258)$ & $.106(.132)$ \\
\hline Cognitive elaboration & $-.116(.073)$ & $-.096(.125)$ & $.052(.412)$ \\
\hline Affective trait empathy & $.011(.649)$ & $-.028(.625)$ & $.003(.958)$ \\
\hline Cognitive trait empathy & $-.009(.881)$ & $.073(.204)$ & $-.059(.316)$ \\
\hline Text case style & $.029(.588)$ & $.193(.000)$ & $-.091(.091)$ \\
\hline Text case subject & $.061(.256)$ & $-.051(.325)$ & $.008(.874)$ \\
\hline Affective state empathy & $-.046(.553)$ & $-.067(.379)$ & $.109(.159)$ \\
\hline Cognitive state empathy & $.053(.529)$ & $-.029(.723)$ & $.064(.447)$ \\
\hline Text $\quad$ case $\quad$ style & $-.063(.400)$ & $-.191(.008)$ & $.159(.032)$ \\
\hline Affective state empathy & & & \\
\hline Text case style & $-.023(.755)$ & $.107(.141)$ & $-.129(.082)$ \\
\hline Cognitive state empathy & & & \\
\hline$\Delta R^{2}$ step 5-6 & .006 n.s. & $.019 *$ & .013 n.s. \\
\hline$R^{2}$ step 6 & .048 n.s. & $.111 * * *$ & .067 n.s. \\
\hline
\end{tabular}

The moderation effect on the propositional model is shown on the left, and the moderation effect on the situational model on the right in Figure 1. The dotted line on the left shows that at low levels of affective state-empathy, the propositional model was stronger after reading psycho-narrative cases than after reading externally focalized cases $\left(B_{\text {Low }}=0.541, p<.001\right)$. The solid line on the left, on the other hand, shows that at high levels of affective state-empathy the text style had no significant effect on the propositional model $(B$ High $=0.015, p=.899)$. The dotted line on the right shows that at low levels of affective state-empathy, the situational model was stronger after reading externally focalized cases $\left(B_{\text {Low }}=-0.413, p=.003\right)$ while at high levels of affective empathy there was no significant difference between externally focalized and psycho-narrative cases $\left(B_{\mathrm{High}}=0.097, p=.523\right)$. 


\section{Figure 1}

Simple Slope Analysis for the Effect of Text Case Style and Affective State-Empathy on Propositional and Situational Cognitive Model

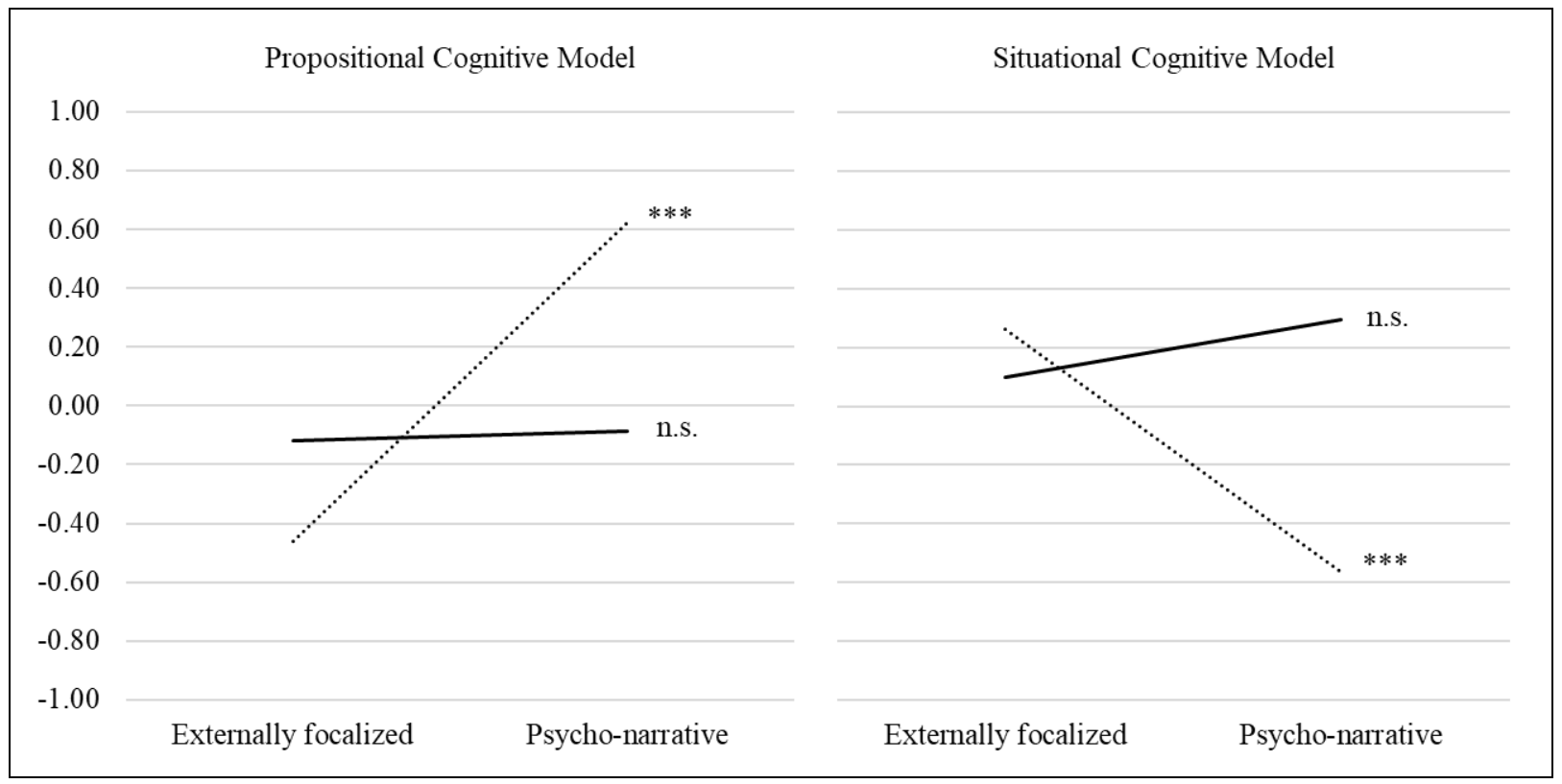

Note. Dotted Line $=$ Low Affective State-Empathy, Solid Line $=$ High Affective State-Empathy High; $* * * p<$ .001, n.s. not significant.

\section{Discussion}

The present study examined the effects of text style (psycho-narrative and externally focalized), text subject (dyscalculia and test anxiety) and empathy on the cognitive modeling of text-based diagnostic cases. Building on theoretical models of teacher diagnostics and individual information processing, we utilized the construction-integration theory to measure text-based cognitive modeling as a central component of diagnostic competence. We hypothesized a positive effect of 1) psycho-narrative text style and 2) the text subject of test anxiety on the strength of verbatim, propositional and situational models, as well as a positive effect of 3) affective state-empathy and 4) cognitive trait- and state-empathy on the strength of cognitive models. Furthermore, we hypothesized that there would be 5) a moderation effect of stateempathy on the relationship of text style and strength of cognitive models. In summary, we found a significant main effect of the text style on the strength of the verbatim, propositional, and situational models, but no effect of cognitive and affective trait- and state-empathy. Nevertheless, we found an interaction effect of text style and state-empathy that lead to interesting conclusions for designing text-based cases and for the role of empathy in processing diagnostic information.

\section{Text Characteristics and Cognitive Modeling}

Based on empathy research, our first hypothesis stated that psycho-narrative text cases would support building cognitive models more than externally focalized text cases. Our results show that students who read psycho-narrative text cases built a stronger propositional model than 
students who read externally focalized text cases. Therefore, hypothesis 1 can be maintained for the propositional model, but not for the verbatim and the situational model.

This is in line with previous psycholinguistic research (Gernsbacher et al., 1992), but not with the existing literature on design principles for text-based cases in teacher education. Specifically, Kiel et al. (2014) suggest, that enriching texts with social information increases extrinsic cognitive load, introducing additional difficulties to information processing. Even though we did not measure cognitive load, our results suggest, that in the context of teacher diagnostics, social information in text cases might be part of the intrinsic or germane load, i.e. an integral part of the learning task. According to Paas et al. (2010), cognitive load does not simply increase with the information added, but with the interaction of information elements and their relevance for the cognitive schema, that a specific task demands. In teacher diagnostics, the most prominent demand is acquiring information about students who might have problems in their learning process or show stereotype-inconsistent learning behavior. In the text cases, the provided social information might have acted as a cue, guiding the selection and organization of information towards building person centered informational 'chunks'. This explanation is consistent with Sherman et al. (2004), who report an increase in memory detail, when processing stereotype-inconsistent information. This mechanism would also explain, why the psycho-narrative text cases affect the propositional model, which requires more detail to be accurate, but not the situational model. Furthermore, Pendry and Macrae (1999) found that the stereotype-inconsistency effect increased, when people assumed an observed social group to be heterogeneous. Since teachers' diagnostics builds on this assumption, social information highlighting individual differences might be beneficial for building accurate cognitive models of text-based cases. However, in our study the sheer amount of information to be processed did not notably differ between the experimentally manipulated text styles (number of sentences and words). Future studies could focus on this and on the specific relationship between the type of information given and the cognitive load.

\section{Empathy and Cognitive Modeling}

Empathy is important for teachers' diagnostics, as it enables teachers to understand their students' emotional states and way of thinking. Accordingly, we hypothesized positive direct effects of affective state-empathy, cognitive trait-empathy and cognitive state-empathy on the strength of the cognitive models. Furthermore, based on Salem et al. (2017) and Lombardo et al. (2007), we hypothesized a moderation effect of state-empathy on the effect of text style on cognitive model strength.

Neither affective nor cognitive trait- or state-empathy had a main effect on the strength of the cognitive models, which is why we must reject hypotheses 3 and 4 . Furthermore, the regression models for the verbatim and the situational model were not significant, limiting the generalizability of the results. Since the positive effect of empathy on memory formation is well established, this result is rather puzzling. Our study protocol was similar to existing studies that have implemented self-report scales, a recognition test, a short interval between supplying information and testing its accurate memorization (Gao et al., 2016; Wagner et al., 2015) and even short stories (Stiller \& Dunbar, 2013). However, our study differs in terms of information quantity and complexity. Our diagnostic cases were considerably longer (about 650 words) than Stiller and Dunbar's (2013) short stories about asking for directions (about 200 words), 
and more complex Lombardo et al. (2007), for example, used word lists with no more than 10 adjectives). This suggests that empathy has a positive effect on memory formation only under certain circumstances, e.g. when people can effectively apply heuristics to judgment tasks. Heuristics are short decision rules, e.g. take the most familiar, that are employed to judge probabilities in speedy and uncertain situations (Gigerenzer \& Gaissmaier, 2011). For example, empathy has been shown to be related to the 'ease of self-simulation' heuristic, where empathy is only employed when the observer does not face a second, cognitively demanding task and when the needs of the target person are straight forward (Chambers \& Davis, 2012). Consequently, the more complex and cognitively demanding experimental material in our study might have inhibited direct effects of empathy on cognitive model strength.

However, we found the hypothesized interaction effect of affective state-empathy and text style which is why we can retain hypothesis 5 . A possible explanation for the interaction effect might be the capacity for self-other differentiation that increases with empathic abilities (Decety \& Lamm, 2006). People with high affective state-empathy can distinguish between one's own and other peoples' feelings and perspectives more effectively. Thus, people with high affective state-empathy might be influenced less by the text style when processing social information.

\section{Text Case Subject and Cognitive Modeling as well as Other Control Variables}

The text cases in our study addressed two prominent learning difficulties (dyscalculia and test anxiety) - namely to control whether empathy interacts with more or less emotion-centered subjects. Our results show no direct or indirect effects of the text case subject on the strength of pre-service teachers' cognitive models. However, we assume that pre-service teachers benefit from getting to know a wide range of learning problems and disorders.

In contrast to the text subject, other control variables - namely age and immersion - had a positive effect on the propositional model, but not on the verbatim and the situational model. Age might have a positive effect because older participants may have more experience with text-based cases, e.g. prior contact with similar learning material or situations in their professional or private life, making it easier to process the information. Immersion had a positive effect on cognitive modeling, which is in line with other research showing that immersive learning material is beneficial for several constructs related to learning activities, e.g. reduced extraneous cognitive load and increased motivation (Syring et al., 2015).

\section{Implications}

Altogether, our study shows that text characteristics and empathy affect processing diagnostic information from text-based cases in pre-service teachers, and therefore adds to the existing knowledge on emotion-centered abilities in teaching. This has implications for teacher education as well as for models of diagnostic competence.

Firstly, for teacher education, our results indicate that text-based cases can effectively stimulate elaborate cognitive processes such as building cognitive models. This means that depending on the instructional goals, diagnostic text cases should be designed differently. Since recent models of diagnostic competence describe accurate cognitive modeling as a central ability, providing cases in psycho-narrative style could foster pre-service teachers' abilities to build propositional models und thus foster their diagnostic competence. While enriching cases 
with social information was beneficial in our study, existing textbooks for designing cases in teacher education suggest otherwise (Kiel et al., 2011). This highlights the importance of further research, explicitly measuring the relationship of text characteristics and cognitive load in teachers' diagnostics.

Secondly, our results also point to the importance of empathy when working with casebased learning environments. According to our results, providing instructions and tasks to stimulate empathy could support processing information from text-based cases. For example, perspective taking can be stimulated by simple prompts, e.g. "When reading the case, try to imagine the situation through the eyes of the people, who are involved." or by regular exercise (van Berkhout \& Malouff, 2016).

Thirdly, for models of diagnostic competence, our study shows that empathy provides preservice teachers with more flexibility regarding their information processing from specific text sources with different structural characteristics. As this flexibility is an important criterion in competence definitions (e.g. Blömeke et al., 2015), we suggest recognizing and further analyzing empathy as a potential component of diagnostic competence.

Finally, cognitive models might be a useful indicator or performance-based outcome for the quality of information processing in the context of teachers' diagnostics. Since many existing measurement instruments are text-based and utilize vignette items (e.g. Klug et al., 2016; Kunter et al., 2017), our results can furthermore be utilized to assess these instruments regarding possible measurement errors due to text style.

\section{Limitations and Further Research}

The present study has limitations that need to be considered when interpreting the results. Firstly, we only indirectly controlled for the participants' prior knowledge on diagnostics, mainly due to the already lengthy experiment, but also because no validated measurement instruments exist. Instead, we applied a random assignment procedure to the experimental groups and measured proxy variables to control for possible confounding by prior knowledge.

Secondly, the scales for affective and cognitive trait-empathy by Heynen et al. (2016) were not very reliable, based on standard rules of thumb. On an individual level, the main consequence of low reliabilities is a higher chance of bias in the measurement. On a group level, this translates to wider confidence intervals of inferred values and thus a lower chance of detecting small but present effects. Furthermore, self-reports of empathy often show similar reliability values (e.g. Carré et al., 2013; Kokkinos \& Kipritsi, 2012), which might stem from bigger interpretation margins when measuring emotional rather than behavioral constructs. Controlling for general working memory capacity could provide additional insights into the predictive power of empathy, since both constructs are often correlated (Gao et al., 2016). Based on the results of the present study, we are currently conducting a replication study including basic cognitive abilities.

Thirdly, the scale for cognitive elaboration also showed a low reliability, which is surprising, since it was developed and validated in the international PISA study (Schiefele et al., 2000). One possible reason for the low reliability might be that participants in our study might not have utilized all the cognitive strategies listed in the scale. As stated above, the low reliability might have resulted in missing a small but present effect. 
Moreover, our sample is not representative of all pre-service teachers. We recruited our sample from four German universities and thus our results cannot be generalized to other contexts without critically reflecting possible cultural and institutional differences in teacher education.

Finally, measuring cognitive models as outcome variable for diagnostic competence is a new methodological approach. Thus, our results should only carefully be compared to other studies on case-based teacher education. An important factor in judging the potential of cognitive models as diagnostic performance measure would be their predictive validity, since stored information should be useful and accessible in other phases of the diagnostic process, for example in the phase of evaluating and reflecting diagnostic situations (Klug et al., 2018).

\section{Conclusion}

Employing text-based cases in teacher education has many convincing features. The low costs, adaptivity and manageable legal demands of producing text-based cases (e.g. technological equipment, consent of the people involved) are highly attractive for teacher education and competence measurement.

Furthermore, many pedagogical and especially diagnostic situations demand processing text-based information (e.g. documentation of observations, reading students homework, review of diagnostic reports). Hence, working with text-based cases provides pre-service teachers with an opportunity to develop their diagnostic competence in a setting that closely resembles situations of teachers' professional activities. In this sense, recognition and verification tests can objectively measure an important part of information processing in the context of teachers' diagnostics.

Empathy proved to be an important factor in developing propositional models about textbased diagnostic cases. If the extent to which pre-service teachers develop cognitive models can be considered an indicator for the quality of their information processing, then activating empathy can be considered beneficial for the selected diagnostic activity. For teachers it is important to know that their diagnostic process might not only be affected by their cognition, but also by their situational ability to understand students' emotional states. Information gained by empathizing can be integrated as additional cues in the diagnostic process. Since empathy can be trained (for an overview: Lam et al., 2011), it could be feasible to conceptualize empathy as a disposition for diagnostic competence and address it in teacher education. 


\section{References}

Appel, M., Gnambs, T., Richter, T., \& Green, M. C. (2015). The Transportation Scale - Short Form (TS-SF). Media Psychology, 18(2), 243-266. https://doi.org/10.1080/15213269.2014.987400

Aryadoust, V. (2019). An integrated cognitive theory of comprehension. International Journal of Listening, 33(2), 71-100. https://doi.org/10.1080/10904018.2017.1397519

Blömeke, S., Gustafsson, J. E., \& Shavelson, R. J. (2015). Beyond dichotomies: Competence viewed as a continuum. Zeitschrift für Psychologie, 223, 3-13. https://doi.org/10.1027/2151-2604/a000194

Schneider, J., Bohl, T., Kleinknecht, M., Kuntze, S., Rehm, M., \& Syring, M. (2016). Unterricht analysieren und reflektieren mit unterschiedlichen Fallmedien: Ist Video wirklich besser als Text? [Analyzing and reflecting the classroom with different case media: Is video really better than text?] Unterrichtswissenschaft: Zeitschrift für Lernforschung, 44(4), 474-490.

Böhmer, I., Hörstermann, T., Gräsel, C., Krolak-Schwerdt, S., \& Glock, S. (2015). Eine Analyse der Informationssuche bei der Erstellung der Übergangsempfehlung: Welcher Urteilsregel folgen Lehrkräfte? [An analysis of information search in the process of making school tracking decisions: Which judgment rule do teachers apply?] Journal for Educational Research Online/Journal für Bildungsforschung Online, 7(2), 59-81.

Bradley, J. H., Paul, R., \& Seeman, E. (2006). Analyzing the structure of expert knowledge. Information \& Management, $43(1), \quad 77-91$. https://psycnet.apa.org/doi/10.1016/j.im.2004.11.009

Calvo, M. G., Castillo, M. D., \& Schmalhofer, F. (2006). Strategic influence on the time course of predictive inferences in reading. Memory \& Cognition, 34(1), 68-77. https://doi.org/10.3758/BF03193387

Carré, A., Stefaniak, N., D'ambrosio, F., Bensalah, L., \& Besche-Richard, C. (2013). The Basic Empathy Scale in adults (BES-A): Factor structure of a revised form. Psychological Assessment, 25(3), 679-691 https://doi.org/10.1037/a0032297

Chambers, J. R., \& Davis, M. H. (2012). The role of the self in perspective-taking and empathy: Ease of self-simulation as a heuristic for inferring empathic feelings. Social Cognition, 30(2), 153-180. https://doi.org/10.1521/soco.2012.30.2.153

Chernikova, O., Heitzmann, N., Fink, M. C., Timothy, V., Seidel, T., \& Fischer, F. (2019). Facilitating diagnostic competences in higher education - A meta-analysis in medical and teacher education. Educational Psychology Review, 32, 157-196. https://doi.org/10.1007/s10648-019-09492-2

Decety, J., \& Lamm, C. (2006). Human empathy through the lens of social neuroscience. The Scientific World Journal, 6, 1146-1163. https://doi.org/10.1100/tsw.2006.221

Eisenberg, N. (2000). Emotion, regulation, and moral development. Annual Review of Psychology, 51(1), 665-697. https://doi.org/10.1146/annurev.psych.51.1.665

Frazier, P. A., Tix, A. P., \& Barron, K. E. (2004). Testing moderator and mediator effects in counseling psychology research. Journal of Counseling Psychology, 51(1), 115-134. https://doi.org/10.1037/0022-0167.51.1.115 
Gaesser, B. (2013). Constructing memory, imagination, and empathy: A cognitive neuroscience perspective. Frontiers in Psychology, 3, 576-584. https://doi.org/10.3389/fpsyg.2012.00576

Gernsbacher, M. A., Goldsmith, H. H., \& Robertson, R. R. (1992). Do readers mentally represent characters' emotional states? Cognition \& Emotion, 6(2), 89-111. https://doi.org/10.1080/02699939208411061

Gigerenzer, G., \& Gaissmaier, W. (2011). Heuristic decision making. Annual Review of Psychology, 62, 451-482. https://doi.org/10.1146/annurev-psych-120709-145346

Gao, Z., Ye, T., Shen, M., \& Perry, A. (2016). Working memory capacity of biological movements predicts empathy traits. Psychonomic Bulletin \& Review, 23(2), 468-475. https://doi.org/10.3758/s13423-015-0896-2

Glock, S., Krolak-Schwerdt, S., Klapproth, F., \& Böhmer, M. (2013). Beyond judgment bias: How students' ethnicity and academic profile consistency influence teachers' tracking judgments. Social Psychology of Education: An International Journal, 16(4), 555-573. https://doi.org/10.1007/s11218-013-9227-5

Hellmann, K. A. (2015). Diagnostische Kompetenz als Perspektivenübernahmefähigkeit. Der Einfluss von Lehrerfahrung, Vertrautheit mit dem Urteilsobjekt und Aufgabendesign auf die Urteilsgüte [Diagnostic competence as perspective taking. Effects of teaching experience, knowledge of object of judgement and task design on diagnostic accuracy](DOI: 10.6094/UNIFR/10765) [DoctoralDissertation, Albert-LudwigsUniversität Freiburg]. FreiDok.

Heynen, E. J. E., Van der Helm, G. H. P., Stams, G. J. J. M., \& Korebrits, A. M. (2016). Measuring empathy in a german youth prison: A validation of the german version of the basic empathy scale (BES) in a sample of incarcerated juvenile offenders. Journal of Forensic Psychology Practice, 16(5), 336-346. https://doi.org/10.1080/15228932.2016.1219217

Jose, P. E. (2013). ModGraph-I: A programme to compute cell means for the graphical display of moderational analyses: The internet version (Version 3.0). Victoria University of Wellington. https://psychology.victoria.ac.nz/modgraph/

Kiel, E., Kahlert, J., Haag, L., \& Eberle, T. (2011). Herausfordernde Situationen in der Schule [Challenging situations in school]. Klinkhardt.

Kiel, E., Kahlert, J., \& Haag, L. (2014). Was ist ein guter Fall für die Aus- und Weiterbildung von Lehrerinnen und Lehrern? [What is a good case for teacher education?]. Beiträge zur Lehrerinnen-und Lehrerbildung, 32(1), 21-33.

Kintsch, W. (1992). How readers construct situation models for stories: The role of syntactic cues and causal inferences. In A. F. Healy, S. M. Kosslyn, \& R. M. Shiffrin (Eds.), Essays in honor of William K. Estes, Vol. 1. From learning theory to connectionist theory; Vol. 2. From learning processes to cognitive processes (pp. 261-278). Lawrence Erlbaum Associates, Inc.

Klug, J., Schultes, M. T., \& Spiel, C. (2018). Assessment at school - Teachers' diary-supported implementation of a training program. Teaching and Teacher Education, 76, 298-308. https://doi.org/10.1016/j.tate.2017.10.014 
Klug, J., Bruder, S., Schmitz, B. (2016). Which variables predict teachers' diagnostic competence when diagnosing students learning behavior at different stages of a teacher's career? Teachers and Teaching: Theory and Practice, 22(4), 461-484. https://doi.org/10.1080/13540602.2015.1082729

Klug, J., Bruder, S., Kelava, A., Spiel, C., \& Schmitz, B. (2013). Diagnostic competence of teachers: A process model that accounts for diagnosing learning behavior tested by means of a case scenario. Teaching and Teacher Education, 30, 38-46. https://doi.org/10.1016/j.tate.2012.10.004

Knutson-Miller, K. K. (2001). Teacher perspective-taking: Developmental and individual differences. Educational Research Quarterly, 25(2), 22-34.

Kokkinos, C. M., \& Kipritsi, E. (2012). The relationship between bullying, victimization, trait emotional intelligence, self-efficacy and empathy among preadolescents. Social Psychology of Education, 15(1), 41-58. https://doi.org/10.1007/s11218-011-9168-9

Kunter, M., Kunina-Habenicht, O., Baumert, J., Dicke, T., Holzberger, D., Lohse-Bosse, H., Leutner, D., Schulze-Stocker, F., \& Terhart, E. (2017). Bildungswissenschaftliches Wissen und professionelle Kompetenz in der Lehramtsausbildung [Educational science knowledge and professional competence in teacher education]. In C. Gräsel, \& K. Trempler (Eds.), Entwicklung von Professionalität pädagogischen Personals. Entwicklung von Professionalität pädagogischen Personals (pp. 37-54). Springer. https://doi.org/10.1007/978-3-658-07274-2_3

Lam, T. C. M., Kolomitro, K., \& Alamparambil, F. C. (2011). Empathy training: Methods, evaluation practices, and validity. Journal of Multidisciplinary Evaluation, 7(16), 162200.

Leuders, T., Dörfler, T., Leuders, J. \& Philipp, K. (2018). Diagnostic competence of mathematics teachers - Unpacking a complex construct in teacher education and teacher practice. In T. Leuders, J. Leuders \& K. Philipp (Eds.), Diagnostic competence of mathematics teachers - Unpacking a complex construct in teacher education and teacher practice (pp. 3-31). Springer. https://doi.org/10.1007/978-3-319-66327-2

Lombardo, M. V., Barnes, J. L., Wheelwright, S. J., \& Baron-Cohen, S. (2007). Self-referential cognition and empathy in autism. PloS one, 2(9), 1-11. https://doi.org/10.1371/journal.pone.0000883

Marks, D., Burman, E., Burman, L., \& Parker, I. (1995). Collaborative research into education case conferences. Educational Psychology in Practice, 11(1), 41-48. https://doi.org/10.1080/0266736950110106

Ostermann, A. (2018). Factors influencing the judgment accuracy of teachers. In T. Leuders, K. Philipp, \& J. Leuders (Eds.). Diagnostic Competence of Mathematics Teachers Unpacking a complex construct in teacher education and teacher practice (pp. 95108). Springer. https://doi.org/10.1007/978-3-319-66327-2

Paas, F., Van Gog, T., \& Sweller, J. (2010). Cognitive load theory: New conceptualizations, specifications, and integrated research perspectives. Educational Psychology Review, 22(2), 115-121. https://doi.org/10.1007/s10648-010-9133-8

Park, W. J., \& Hwang, S. D. (2013). Effects of teachers' knowledge and empathy on educational intervention for ADHD: Focused on the mediating effect of empathy. Journal of 
Korean Academy of Psychiatric and Mental Health Nursing,22(1), 45-55. https://doi.org/10.12934/jkpmhn.2013.22.1.45

Pendry, L. F., \& Macrae, C. N. (1999). Cognitive load and person memory: The role of perceived group variability. European Journal of Social Psychology, 29(7), 925-942. https://doi/10.1002/(SICI)1099-0992(199911)29:7\%3C925::AID-

EJSP973\%3E3.0.CO;2-O

Preston, S. D., \& De Waal, F. B. (2002). Empathy: Its ultimate and proximate bases. Behavioral and Brain Sciences, 25(1), 1-20. https://doi.org/10.1017/s0140525x02000018

Salem, S., Weskott, T., \& Holler, A. (2017). Does narrative perspective influence readers' perspective-taking? An empirical study on free indirect discourse, psycho-narration and first-person narration. Glossa: A Journal of General Linguistics , 2(1), 1-18. http://doi.org/10.5334/gjgl.225

Schaffner, E., \& Schiefele, U. (2013). The prediction of reading comprehension by cognitive and motivational factors: Does text accessibility during comprehension testing make a difference? Learning and Individual Differences, 26, 42-54. https://psycnet.apa.org/doi/10.1016/j.lindif.2013.04.003

Schäfer, S., \& Seidel, T. (2015). Noticing and reasoning of teaching and learning components by preservice teachers. Journal for Educational Research Online, 7(2), 34-58.

Schiefele, U., Artelt, C., Schneider, W. \& Stanat, P. (Eds.). (2004). Struktur, Entwicklung und Förderung von Lesekompetenz. Vertiefende Analysen im Rahmen von PISA 2000 [Structure, development and fostering of reading competence. Deeper analyses of PISA 2000]. VS Verlag für Sozialwissenschaften. https://doi.org/10.1007/978-3-322-810311

Schiefele, U. (1991). Interesse und Textrepräsentation - Zur Auswirkung des thematischen Interesses auf unterschiedliche Komponenten der Textrepräsentation unter Berücksichtigung kognitiver und motivationaler Kontrollvariablen [Interest and text comprehension - On the effect of thematic interest on different components of text representation controlling for cognitive and motivational variables]. Zeitschrift für Pädagogische Psychologie, 5(4), 245-259.

Schiefele, U. (1990). Thematisches Interesse, Variablen des Lernprozesses und Textverstehen [Thematic interest, variables of the learning process and text comprehension]. Zeitschrift für Experimentelle und Angewandte Psychologie, 37(2), 304-332.

Schmalhofer, F., \& Glavanov, D. (1986). Three components of understanding a programmer's manual: Verbatim, propositional and situational representations. Journal of Memory and Language, 25, 279-294. https://doi.org/10.1016/0749-596X(86)90002-1

Seidel, T., Blomberg, G., \& Stürmer, K. (2010). „Observer“ - Validierung eines videobasierten Instruments zur Erfassung der professionellen Wahrnehmung von Unterricht [,Observer" - Validation of a video-based instrument to capture professional vision in the classroom]. Zeitschrift für Pädagogik, 56, Beiheft, 296-306.

Shen, L. (2010). On a scale of state empathy during message processing. Western Journal of Communication, 74(5), 504-524. https://doi.org/10.1080/10570314.2010.512278

Sherman, J. W., Conrey, F. R., \& Groom, C. J. (2004). Encoding flexibility revisited: Evidence for enhanced encoding of stereotype-inconsistent information under cognitive load. 
Social

Cognition,

22(2),

$214-232$. https://psycnet.apa.org/doi/10.1521/soco.22.2.214.35464

Singer, M., \& Kintsch, W. (2001). Text retrieval: A theoretical exploration. Discourse Processes, 31(1), 27-59. https://psycnet.apa.org/doi/10.1207/S15326950dp3101_2

Snodgrass, J. G., \& Corwin, J. (1988). Pragmatics of measuring recognition memory: Applications to dementia and amnesia. Journal of experimental psychology, 117(1), 34-50. https://doi.org/10.1037/0096-3445.117.1.34

Stanislaw, H., \& Todorov, N. (1999). Calculation of signal detection theory measures. Behavior Research Methods, Instruments, \& Computers, 31(1), 137-149. https://doi.org/10.3758/BF03207704

Stiller, J., \& Dunbar, R. I. (2007). Perspective-taking and memory capacity predict social network size. Social Networks, 29(1), 93-104. https://doi.org/10.1016/j.socnet.2006.04.001

Strauss, S., \& Shilony, T. (1994). Teachers' models of children's minds and learning. In Hirschfeld, L. A., \& Gelman, S. A. (Eds.). Mapping the mind: Domain specificity in cognition and culture (pp. 455-473). Cambridge University Press. https://doi/10.1017/CBO9780511752902.019

Stühring, J., \& Köppe, T. (2016). Two approaches to defining internal, external, and zero focalization. Semiotica, 2016(210), 191-207.

https://doi.org/10.1515/sem-2016-0056

Syring, M., Bohl, T., Kleinknecht, M., Kuntze, S., Rehm, M., Schneider, J. (2015). Videos oder Texte in der Lehrerbildung? Effekte unterschiedlicher Medien auf die kognitive Belastung und die motivational-emotionalen Prozesse beim Lernen mit Fällen [Videos or texts in teacher education? Effects of different media on the cognitive load and motivational-emotional processes while learning with cases]. Zeitschrift für Erziehungswissenschaft, 18, 667-685. https://doi.org/10.1007/s11618-015-0631-9

Teuscher, D., Moore, K. C., \& Carlson, M. P. (2016). Decentering: A construct to analyze and explain teacher actions as they relate to student thinking. Journal of Mathematics Teacher Education, 19(5), 433-456. https://doi.org/10.1007/s10857-015-9304-0

Trittel, M., Gerich, M., \& Schmitz, B. (2014). Training prospective teachers in educational diagnostics. In S. Krolak-Schwerdt, S. Glock, \& M. Böhmer (Eds.), Teachers' professional development. Assessment, training, and learning (pp. 63-78), Sense. https://doi.org/10.1007/978-94-6209-536-6_5

Tsoulopas, C. N., Carson, R. L., \& Matthews, R. A. (2014). Personal and school cultural factors associated with the perceptions of teachers' efficacy in handling student misbehavior. Psychology in the Schools, 51, 164-180. https://doi.org/10.1002/pits.21739

van Berkhout, E. T., \& Malouff, J. M. (2016). The efficacy of empathy training: A metaanalysis of randomized controlled trials. Journal of Counseling Psychology, 63(1), 3241. https://doi.org/10.1037/cou0000093

Wagner, U., Handke, L., \& Walter, H. (2015). The relationship between trait empathy and memory formation for social vs. non-social information. BMC Psychology, 3(2), 1-8. https://doi.org/10.1186/s40359-015-0058-3 
Wang, Z., Sabatini, J., O’Reilly, T., \& Feng, G. (2017). How individual differences interact with task demands in text processing. Scientific Studies of Reading, 21(2), 165-178. https://doi.org/10.1080/10888438.2016.1276184

Wedel, A., Müller, C. R., Pfetsch, J., \& Ittel, A. (2020). Entwicklung diagnostischer Kompetenz in der Lehramtsausbildung - Effekte problemorientierten Lernens mit Textfällen [Development of diagnostic competence in teacher education - effects of problem-based learning with text-based cases]. In I. Gogolin, B. Hannover, \& A. Scheunpflug (Eds.), Evidenzbasierung in der Lehrkräftebildung. Edition der Zeitschrift für Erziehungswissenschaft Band 4 (pp. 95-122). Springer VS. https://doi.org/10.1007/978-3-658-22460-8_5

Wedel, A., Müller, C. R., Pfetsch, J., \& Ittel, A. (2019). Training teachers' diagnostic competence with problem-based learning: A pilot and replication study. Teaching \& Teacher Education, 86, 1-14. https://doi.org/10.1016/j.tate.2019.102909 